\title{
Cerca de la vida y del sentir del pueblo. Gustavo Cochet (1894-1979)
}

\author{
Sabina Florio \\ Universidad Nacional de Rosario
}

\begin{abstract}
Resumen
Gustavo Cochet (1894-1979) es un artista clave de nuestra ciudad. Miembro de la primera generación de creadores locales, exhibe un particular acercamiento al realismo que excede las caracterizaciones precedentes acerca del arte de Rosario. La presencia de Atalaya (Alfredo Chiabra Acosta) y del círculo de artistas próximos a Martín Malharro en el ambiente cultural rosarino, frecuentado por el joven creador, su participación activa en los espacios culturales de Barcelona y París -desde mediados de la década del ' 10 - y su adhesión militante a la República Española, labraron su sensibilidad marcada por una firme postura libertaria y una identificación plena del arte con la vida cotidiana.
\end{abstract}

Palabras clave: Gustavo Cochet - Arte y anarquismo - Modernidad y tradición

\section{Abstract}

Gustavo Cochet (1894-1979) is a key artist of our city. Member of the first generation of local artists, sample a peculiar approach to realism that exceeded the previous characterizations of art in Rosario. The presence of Atalaya (Alfredo Chiabra Acosta) and the circle of nearby artists to Martín Malharro in Rosario's cultural circles, frequented by the young painter, his active participation in the cultural spaces of Barcelona and Paris (since of mid '10) and his militant adherence to the Spanish Republic, carved his sensitivity, marked by a strong anarchist posture and a full identification of art with the daily life. Key words:Gustavo Cochet - Art and anarchism - Modernity and tradition

"Es con nuestro ejemplo cotidiano que hemos de proclamar nuestras ideas""

\section{Una “célula” del ambiente del arte de Rosario}

Gustavo Cochet nació en Rosario el seis de mayo de 1894. Fue el mayor de seis hermanos fruto del matrimonio constituido por Víctor Cochet -maestro francés-y Marquesa

1 COCHET, Gustavo, Consejos, Barcelona, 1 de abril, 1937 (Archivo Cochet, Museo G. Cochet, sin paginar)

FLORIO, Sabina, "Cerca de la vida y del sentir del Pueblo. Gustavo Cochet (18941979)” en Avances del Cesor, Año VIII, N 8, 2011, pp. 9-29. 
Hernández - argentina de raíces mestizas-. Acerca de su infancia el artista señaló “... me crié en una escuela rural, en pleno campo y situada entre Esperanza, Las Tunas y San Jerónimo Norte...", ${ }^{2}$ donde su padre ejercía la función de maestro. ${ }^{3}$

Muy joven, en 1912, se trasladó a Rosario. En palabras de Cochet “... a los diecisiete años me despedí de mis padres en pos de mi oficio". ${ }^{4}$ Ese año fue el de la inauguración oficial de la Biblioteca Argentina en torno a la cual se formó la sociedad cultural "El círculo de la Biblioteca", luego denominada "El Círculo", emprendimiento de gestión cultural que constituyó un momento clave en el proceso de institucionalización del espacio del arte de la ciudad. ${ }^{5}$

Cochet comenzó su formación plástica con César Caggiano quien acababa de regresar de Europa hacia donde se había embarcado en 1911 junto a Carlos Sócrates para estudiar con Giovanni Costetti en Florencia. El estudio de Costetti -pintor, crítico y escritor-era muy concurrido. A él asistieron, años después, Domingo Candia, Manuel Musto y Augusto Schiavoni. El artista italiano se destacaba por ser el introductor del Fauvismo en la Toscana, por su admiración de la obra de Cézanne y por su singular empleo del color al que denominaba "sentimiento de paleta". Como miembro activo del ambiente florentino mantenía relaciones de amistad con Giovanni Papini, Ardengo Soffici y Giorgio De Chirico. Con éste último compartía su pasión por la imaginería simbolista de Arnold Böcklin. ${ }^{6}$

Cuando regresó a Rosario, en 1912, Caggiano, se vinculó con sus pares para emprender la labor de construcción de un ambiente para las artes. En 1914 obtuvo el Primer Premio en el Salón Nacional de Bellas Artes de Buenos Aires, siendo junto a Alfredo Guido y Emilia Bertolé, de los primeros creadores de la ciudad en obtener recompensas en el certamen de mayor legitimación y prestigio del país. ${ }^{7}$

La inexistencia de un programa cultural oficial había llevado a los ciudadanos más

2 COCHET, Gustavo, Diario de un pintor, Castellvi, Santa Fe, 1948,[4 Edición] p. 68.

3 Según Cochet, su padre, era el "único pobre" en esa colonia. Ibídem.

4 Ibídem, p. 199.

5 La Biblioteca Argentina fue creada en 1910 en el marco de los "números conmemorativos del Centenario" realizándose su inauguración oficial el 24 de julio de 1912. En otro orden, Juan Álvarez deja constancia de que "El Círculo" congregó a “... los elementos sociales más significativos de la ciudad". Álvarez, Juan, Historia de Rosario (1689-1939), UNR Editora/Editoral Municipal de Rosario, Rosario, 1998, pp. 474 y 476.

6 Hemos reparado en el ambiente cultural florentino de los años '10 en nuestra Tesis de Doctorado Augusto Schiavoni: obra y fortuna crítica de un artista fuera de lugar, Facultad de Humanidades y Artes, UNR, Rosario, 2009.

7 Bertolé fue distinguida con un premio estímulo en el Salón Nacional en 1915 y Alfredo Guido obtuvo el segundo permio en 1919, en los primeros intentos de formalizaciones históricas sobre el arte de Rosario, tanto Blotta (1925) como Zocchi (1926) perciben a Bertolé, Caggiano y Guido como referentes para sus pares. 
notables a la formación de la ya mencionada asociación cultural "El Círculo" que organizó el Primer Salón de Bellas Artes, en agosto de 1913, donde se reunieron -con motivo de la visita del presidente Sáenz Peña- “... las colecciones particulares de los vecinos...” y “... se exhibieron telas del malogrado Augusto Juan Olivé". ${ }^{8}$ Paralelamente, pequeños grupos de creadores e intelectuales pertenecientes a diversas clases sociales y filiaciones políticas, sintieron la necesidad de crear instancias de producción, exhibición, difusión y circulación de ideas sobre arte, autores y obras.

El escultor Erminio Blotta, como miembro activo de dichos emprendimientos, dejaba constancia por escrito: “... fuimos nosotros los que organizamos el Primer Salón de Arte Nacional ... con el esfuerzo personal de los que ideológicamente nos habíamos reunido al lado de Valenti". ${ }^{9}$ Valenti era uno de los seudónimos de Alfredo Chiabra Acosta, más conocido como Atalaya, quien había arribado a la ciudad en 1911. Blotta calificó a Atalaya como "jefe espiritual" arte de Rosario. Así, “... desde las redacciones de los periódicos, en los pequeños cenáculos de café..." creadores locales. En una nota manuscrita, Cochet, rememora también, “... las tertulias de "La Cosechera"” que "... reunían a la mayoría de los artistas y literatos de Rosario: Abel Rodríguez, Baudraco, Robertacho, 'Atalaya', Cesar Caggiano, Santiago Minturn y otros". ${ }^{12}$

Ricardo Falcón, destacó que a inicios de siglo XX, “... tras haber descendido del tren, Enrique Dickman...” 13 aplicará a Rosario “... el mote de la Barcelona argentina”. ${ }^{14}$ Siguiendo al historiador "... el apelativo se ajusta al hecho de que en esas dos ciudades tuvieron lugar los dos movimientos anarquistas urbanos, más importantes, en términos relativos, en el mundo de la época, de acuerdo al peso específico de cada uno". ${ }^{15}$ La presencia de Atalaya

8 ÁLVAREZ, Juan, Op. Cit., p. 476. Sobre la asociación ver FERNÁNDEZ, Sandra, La Revista El Círculo o el arte de papel. Una experiencia editorial en la Argentina del Centenario, Universidad de Murcia, Murcia, 2010.

9 BLOTTA, Herminio, "El arte pictórico y escultórico en Rosario", La Nación, Buenos Aires, 04/10/1925, p. 12.

10 Ibídem.

11 Ibídem.

12 COCHET, Gustavo, página manuscrita enviada al hijo de Erminio Blotta, fechada el mes de febrero de 1976. Cochet escribió estas notas para el diario La Capital de Rosario, en razón del fallecimiento de su colega y amigo el escultor Erminio Blotta en enero de ese año. Agradezco el material a la nieta del escultor, la escritora y crítica de arte, Beatriz Vignoli.

13 FALCÓN, Ricardo, La Barcelona Argentina. Migrantes, obreros y militantes en Rosario. 18701912, Laborde, Rosario, 2005, p. 165.

14 Ibídem.

15 Ibídem. 
operó como catalizador para un conjunto de creadores que sostendrían, al igual que él, una firme postura libertaria y una identificación completa del arte con la vida cotidiana. Como ha señalado Patricia Artundo “... son las palabras de Henrik Ibsen, recogidas por el mismo Atalaya, las que pueden dar una clave de lectura:

[Él] nos advierte que hasta el día en que su vida no acordó con sus ideas, no pudo crear la obra que su cerebro soñara. Su esfuerzo más grande, confiesa, no fue el de construir sus dramas y sí el de torcer, derrumbar y modelar su vida para que anticipándose como causa de arte, se desenvolviese según el latir de su pensamiento. ${ }^{16}$

Próximo a reconocidos anarquistas de la escena nacional como Ghiraldo y Gilimón y apasionado por el desarrollo de las artes visuales y la literatura, Atalaya editó junto a César Caggiano y a Valentín Thibon de Libian la revista Bohemia. Del semanario se lanzaron 18 números entre inicios de 1913 y 1914. En Bohemia Thibon de Libian publicó sus ilustraciones y Atalaya explicitó sus preferencias por "... algunos nombres que lo han de acompañar a lo largo de lo años: Walt Whitman, ${ }^{17}$ Oscar Wilde y Anatole France". ${ }^{18}$ Según Artundo fue en Bohemia donde "... apareció la que debe haber sido la primer noticia conocida en Rosario sobre el futurismo italiano." 19 La investigadora alude a la nota "una velada futurista" publicada en 1914, hecho que evidencia “... un conocimiento 'temprano' de las vanguardias europeas". ${ }^{20}$

Blotta dejó constancia también del esfuerzo denodado del grupo por otorgarle a la ciudad un carácter cultural acorde a su crecimiento urbano, económico y social. Por esa razón enfatizó: “... me permito recordar los viajes que en segunda clase, pues no había tercera, hicimos a Buenos Aires en el invierno de 1913, para traer personalmente las obras que nos confiaran los amigos Thibon de Libian, Walter de Navazio, Ramón Silva, Delucchi, Daneri, Nicolás Lamanna y Luis Falcini. De Rosario aportaron sus obras César Caggiano, Alfredo Guido, Emilia Bertolé y, por supuesto, las modestas de quien suscribe". ${ }^{21}$ Se trata, en este caso, de creadores que idearon un salón, buscaron personalmente las obras y distribuyeron afiches “... dibujados por los mismos concurrentes". ${ }^{22}$ Cochet enfatizó el hecho de que Blotta fue "... muy activo y dispuesto a cooperar y organizar exposiciones y otros actos en pro

16 ARTUNDO, Patricia (organizador), Atalaya. Actuar desde el arte. El archivo Atalaya, Fundación Espigas, Buenos Aires, 2004, p. 15.

17 En su Diario de un pintor Cochet menciona que los versos de Whitman “... han sido el amor de mi primera juventud", p. 144 y p. 222.

18 Ibídem, p. 25.

19 Ibídem.

20 Ibídem, p. 26.

21 BLOTTA, Herminio, "El arte pictórico...”, Op. Cit. Gustavo Cochet participó de la muestra.

22 Ibídem. 
de la divulgación cultural y artística ... fue él quien reunió obras para el primer salón de Rosario, viajando él mismo a Buenos Aires a visitar personalmente a los pintores reuniendo así las obras que se encargó incluso de transportar, coronando con todo éxito su gestión." ${ }^{, 23}$

Luis Falcini anotó en sus memorias que Atalaya "... durante su estadía en Rosario dio rienda suelta hacia las actividades artísticas, primero como crítico y organizador de muestras de arte nacional. Comenzó a destacarse y organizó la primera muestra de obras de artistas argentinos... " ${ }^{24}$ en el interior del país. Así, se realizó en Rosario el "Primer Salón de Arte Nacional" 25 -no oficial- en la "Casa Blanca", un local de pintura perteneciente a Casildo Souza y que fue conocido por entonces como Petit Salón de Arte Argentino. ${ }^{26}$

En los relatos de los protagonistas notamos una afirmación recurrente, nos referimos a los vínculos de solidaridad y camaradería que explicitan haber cultivado con sus pares, entendiendo a la amistad como energía posibilitadora de realizaciones colectivas. Pensamos que este tipo de vinculaciones podrían estar relacionadas con las simpatías por el ideario anarquista profesadas por algunos de ellos y que extendieron hacia el trato con sus pares amigos. Valores como la honestidad, la ética, la sencillez, el talento, el oficio y la sinceridad -propios del anarquismo- aparecieron en los escritos de Blotta, Cochet y Musto, fundamentos que operaron como guía por sobre los principios de originalidad y novedad sustentados por las vanguardias.

Cochet sostendrá años después:

Abomino de lo nuevo en su sentido de actualidad desabrida ... Apoyándome en el pasado doy una gran zancada y me voy hacia lo futuro ... Por lo menos en arte, creo que hoy no hay salvación posible para un artista que se encasille en un ismo, cualquiera este sea. ${ }^{27}$

Al respecto, Manuel Musto, anotó tempranamente en su cuaderno personal de notas “... nosotros como no somos futuristas, no somos tampoco restauradores del anciano (sic) régimen...", ${ }^{28}$ posicionándose como creador en una zona equidistante entre la vanguardia y la

23 COCHET, Gustavo, Op. Cit.

24 FALCINI, Luis, Falcini. Itinerario de una vocación, Losada, Buenos Aires, 1975, p. 108.

25 BLOTTA, Herminio, "El arte pictórico..., Op. Cit.

26 La datación de la muestra difiere según los autores, Blotta (1925) lo fecha en el invierno de 1913, Slullitel en su Cronología del arte en Rosario (1968, p.36) lo sitúa en 1912. María Eugenia Spinelli (2008, p. 143), a partir de una reseña publicada en el periódico rosarino La Capital (29/05/1914) infiere que se realizó en mayo de 1914.

27 COCHET, Gustavo, Catálogo Exposición de pintura de Gustavo Cochet, Galería Müller, Buenos Aires, Octubre 1944, p. 11 y p. 51.

28 MUSTO, Manuel, Cuaderno personal de notas, p. 57. El cuaderno no está fechado, sin embargo por su contenido y a la luz de ciertos datos biográficos que aparecen allí pensamos que fue escrito a 
Academia. Una idea similar sostuvo Julio Payró para pensar a la figura de Cochet. Consciente de que la totalidad de las propuestas artísticas de los primeros años del siglo XX no podían ser homologadas a la noción de vanguardia, Payró, en su libro Veintidós pintores argentinos de 1944 señaló que: “... grave inexactitud sería considerar a Cochet como un 'pasatista': su realismo tiene marcados caracteres de novedad, por mucho que se relacione con una serie de manifestaciones tradicionales, y, así, ni la Academia ni los vanguardistas intransigentes colocan a este pintor en el lugar que le corresponde, una porque es demasiado avanzado, y otros, porque les parece demasiado confundido con la retaguardia". ${ }^{29}$ Así, al igual que Musto y Cochet, hay un conjunto importante de artistas pertenecientes a la modernidad estética rosarina temprana, cuyas proposiciones plásticas han sido desestimadas o subvaloradas por no haberse desenvuelto en el ámbito de las rupturas estrepitosas..$^{30}$

Además de la presencia de Atalaya fueron los discípulos de Martín Malharro quienes constituyeron una referencia productiva para nuestros creadores. Como ha señalado Laura Malosetti Costa, Malharro desplegó “... un nacionalismo original, de corte anarquista y moderno, en el cual propone la posibilidad de una pintura nacional a partir de una íntima comunión con la naturaleza del país". Así el artista recomendaba olvidar lo "... aprendido en las escuelas europeas" y “... frente a frente a la naturaleza..." imaginar sus misterios. ${ }^{31}$ En un mismo sentido, Cochet, a lo largo de toda su vida, sostuvo la necesidad de "enfrentar el paisaje" para llegar a su "hondo sentimiento poético", ${ }^{32}$ afirmando que "... el verdadero artista no está obligado a sintetizar nada, ni reducir nada. Su arte, su gran arte está precisamente, en que acusa, acentúa, agudiza, hace vibrar o exalta y aumenta todo lo que ve con su sentimiento profundamente humano y poético". ${ }^{33}$

Malharro había establecido estrechos vínculos con los jóvenes artistas que sintonizaban con su espíritu combativo, nos referimos a Luis Falcini quien lo consideraba “... el maestro espiritual que necesitábamos y el rector de nuestra adolescencia vital e impulsiva.... ${ }^{34}$ a

inicios de los años '20. Al respecto ver: FLORIO, Sabina, "Manuel Musto. La pintura como expresión de las pasiones y las emociones", en SARTOR, Mario (director), Studi latinoamericani. Estudios Latinoamericanos, FORUM, 2005, Udine, pp. 121-132.

29 PAYRÓ, Julio, Veintidós pintores argentinos, Editorial Poseidón, Buenos Aires, 1944, p. 18.

30 Hemos desarrollado esta problemática en nuestra tesis doctoral "Augusto Schiavoni: obra y fortuna crítica de un artista fuera de lugar", Op. Cit.

31 MALOSETTI COSTA, Laura, "Las artes plásticas entre el ochenta y el centenario" en Burucúa, José E. (director), Nueva Historia Argentina. Arte, Sociedad y política, Sudamericana, Buenos Aires, 1999, p. 206.

32 COCHET, Gustavo, Entre el llano y la sierra, Castellvi, Santa Fe, 1947, p. 93. [Una nota del autor aclara que fue terminado de escribir en 1942].

33 COCHET, Gustavo, Diario...,Op. Cit., p. 17.

34 FALCINI, Luis, Falcini. Itinerario..., Op. Cit., p. 27. 
Ramón Silva, Walter de Navazio y Nicolás Lamanna, todos éstos presentes en el Petit Salón de Rosario. En sintonía con ese clima de camaradería e ideas estéticas sobre el arte argentino, a los veinte años, Cochet viajó a Buenos Aires donde frecuentó a Walter de Navazio y Thibón de Libian. Con ese bagaje de prácticas y experiencias colectivas, atravesadas por la concepción anarquista del arte y posicionadas entre la modernidad y la tradición, Gustavo Cochet, en 1915, tras realizar una exposición en la Cooperativa Artística de Rosario, se trasladó al viejo continente para completar sus estudios.

\section{Entre París, Barcelona y Rosario}

Europa, a comienzos de los años ' 10 , continuaba operando como lugar a descubrir. Un flujo continuo caracterizó a esos años en los que las principales ciudades europeas funcionaban como lugares-destino para pintores, escritores y músicos procedentes de distintos lugares de América Latina. Su primer destino fue Barcelona, según el artista, había arribado con:

... mis herramientas de pintor, unos pocos trapos y todavía más escasas pesetas ... subí a un tranvía tomando una resolución un tanto trágicamente: jiré hasta donde termine su trayecto, allí me plantaré y que pase lo que pase! En el barrio 'Poble Nou', donde me planté, encontré ayuda y amistad. ${ }^{35}$

En Barcelona encontró un ambiente cultural dinámico y complejo. Debido a los estragos de la primera guerra mundial la ciudad se había convertido en un sitio de asentamiento de artistas e intelectuales. Allí se encontraban los uruguayos Joaquín Torres García y Rafael Barradas, el matrimonio Delaunay, Albert Gleizes, Francis Picabia y Arthur Cravan, entre otros. A comienzos de 1917, pasaron los argentinos Alfredo Guttero y Pablo Curatella Manes. ${ }^{36}$

Cochet, comenzó a trabajar en la Galería Dalmau, espacio frecuentado por Picasso, Torres García, Nonell y Miró. La galería venía desarrollando desde 1911 un programa expositivo del arte moderno. Allí, en 1919, realizó su primera exposición individual. Al mismo tiempo, su amigo Pere Daura lo inició en el oficio del grabado. Según el rosarino: “... en Barcelona me hice al trabajo, al sentido artesanal del oficio". También conoció a Francisca Alfonso su modelo, esposa, "ángel protector" y "musa de la inspiración”, con quien se casó en 1921 y tuvo a su hijo Fernando al año siguiente. ${ }^{37}$

En 1921 se trasladó a París, convocado por el gobierno Francés para realizar el servicio militar. La capital francesa operó como punto de convergencia de un conjunto muy impor-

35 BRUNIARD, Mele, SERÓN, Eduardo A. y ELLENA, Emilio, Gustavo Cochet, Estudio gráfico, Buenos Aires, 1968, sin paginar.

36 Sobre la estadía europea de los artistas modernos rioplatenses ver ARTUNDO, Patricia, Artistas modernos rioplatenses en Europa 1911/1924. La experiencia de la vanguardia, Malba-Colección Constanti, Buenos Aires, 2002.

37 COCHET, Gustavo, Diario ..., Op. Cit, p. 92. 
tante de artistas latinoamericanos. Por entonces circulaban allí los argentinos Xul Solar, Emilio Pettoruti, Pablo Curatella Manes y Domingo Candia.

En París sostuvo una actividad intensa de formación -asistió al taller de Maurice Loutril y visitó Museos para estudiar en múltiples obras ${ }^{-38}$ y de producción -pintó la gente, los barrios obreros y los suburbios-. En 1923 envió sus óleos Paisaje y Retrato de mujer al VI Salón de Otoño de Rosario, presentó su primera exposición individual en la Galería Fabre de París y siguió participando en muestras realizadas en Barcelona. En 1924 participó del Salón de los Independientes. En 1926 expuso en el Salón de Otoño de París y en la Galería Chapellier de Bruselas. En 1927 presentó una muestra en la Galería Fabré de París y en la Sala Parés de Barcelona, también nació su hijo Victor que vivió sólo unos meses.

En 1928, tras exponer en Barcelona, en el Museo de Arte Moderno de Madrid, en Bilbao y Perpigñán, regresó a Rosario por seis meses. Durante su estadía compartió una casa con Santiago Minturn Zerva y frecuentó a sus compañeros Juan Berlengieri, Alfredo Guido, Manuel Musto y Augusto Schiavoni. La ciudad contaba con un espacio plástico rico en matices, según Juan Zocchi por entonces ya se podía afirmar la presencia de "una cultura pictórica" 39 propia. Siguiendo a Zocchi, “... después del cereal ... la única gloria de Rosario es la pintura ... donde coexisten muchos modos, escuelas y tendencias ... el impresionismo renovado y personalizado de Musto...", ${ }^{40}$ el "geometrismo expresionista" de Julio Vanzo, "el primitivismo estilizado" de Lucio Fontana, el "... subjetivismo de Alfredo Guido, prolongado y diferenciado en Luis Ouvrard" y -agregamos nosotros- el realismo sensible de Gustavo Cochet ${ }^{41}$ y la figuración de nuevo cuño de Augusto Schiavoni.

En agosto de 1928 realizó una exposición en la Cooperativa Artística acompañada con un catálogo prologado por Caggiano, donde el maestro destacaba que siendo adolescente su discípulo “... ya revelaba ser un pintor de temperamento y promisor". ${ }^{42}$ Luego retornó a Barcelona y se dedicó a la realización de los decorados para la Exposición Internacional. En

38 Según el artista, dedicó "más de cuatro años" a copiar a "casi todos los impresionistas". Ibídem, p. 167.

39 ZOCCHI, Juan, “Una cultura pictórica en Rosario", en Reflejos, 20/09/1926, 3 Sección, Archivo de Manuel Ferrer Dodero, sin paginar.

40 En diversos trabajos hemos estudiado la propuesta de Musto, la cual excede el impresionismo que aparece conjugado con procedimientos derivados del posimpresionismo y el simbolismo. FLORIO, Sabina, "Manuel Musto: una manera de armonizar los actos con las aspiraciones íntimas", en Separata, Centro de Investigaciones del Arte Argentino y Latinoamericano, Facultad de Humanidades y Artes, Universidad Nacional de Rosario, Año V, No 9, 2005, pp. 3-18.

41 En su artículo de 1925, Erminio Blotta augura para Cochet y Musto "un lugar promisor" en el arte de Rosario.

42 "El pintor Gustavo Cochet inaugurará esta tarde una exposición de sus obras", Rosario, Democracia, 20/08/1928. Archivo Cochet, sin paginar. 
1929 regresó a París, obtuvo el Premio de Grabado en el Salón Nacional de Buenos Aires y participó de la Exposición de Arte Moderno Nacional y Extranjero en la Galería Dalmau.

En marzo de 1930 Joaquín Torres García escribió un hermoso artículo publicado en la prensa parisina denominado "Gustavo Cochet. Pintor argentino". Allí sitúa a su par rosarino "en el plano moderno" destacando la cualidad de considerar más “... el aspecto plástico que el descriptivo de la pintura". Lo define como un pintor "... perfectamente adaptado al ambiente de París" y destaca de su obra el "... dibujo firme y las formas solidamente construidas". Siendo, sus motivos pictóricos: “.... aspectos de suburbio, muelles, fábricas, obreros, gentes del pueblo y del trabajo...", temas “... que piden para ser representados un arte viril como el de Cochet". ${ }^{43}$

Cochet estableció lazos con Torres García, quien lo interiorizó de sus indagaciones estéticas en torno al constructivismo. Ambos sostuvieron un estrecho vínculo de amistad a través de distintas vías, el trabajo conjunto, diálogos y cartas. Cabe destacar aquí la posición del rosarino con respecto a la problemática del compromiso en el campo del arte: “... hoy poseemos tantos medios de difusión y al alcance de todos, es absurdo pedirle al arte que sirva de propaganda, ... lo que siempre ha servido para propagar una idea ha sido predicándolo con el ejemplo". ${ }^{44}$ Así, el autor, proponía, al igual que Torres García, atender a la calidad de las proposiciones plásticas como condición para obtener una obra lograda y cultivar una posición ética en la articulación del arte con la propia vida.

\section{Joyas del arte pictórico}

En 1931 regresó a Rosario prolongando su estadía por tres años. 1932 resultó ser un año muy intenso para Cochet quien publicó su Diario de un pintor, ${ }^{45}$ realizó una importante muestra individual en la ciudad, expuso en Buenos Aires junto a Minturn Zerva y Alberto Pedrotti, invitado por Emilio Pettoruti y participó de la Exposición Conmemorativa del Cincuentenario de la ciudad de La Plata. Según Córdova Iturburu la exposición de Arte de La Plata fue "... la más completa que se realizó en el país..." incluyendo a Cochet entre los "envíos más brillantes" en sintonía con el arte nuevo. ${ }^{46}$ En ese sentido Diana Weschler

43 TORRES GARCÍA, Joaquín, “Gustavo Cochet, pintor Argentino”, Op. Cit.

44 COCHET, Gustavo, Diario..., Op. Cit, p. 97.

45 Con 40 xilografías y publicado por la editorial rosarina Federico Luft.

46 Artículo publicado bajo el título "La exposición de Arte de La Plata fue la más completa que se realizó en el país" en el periódico porteño Critica en noviembre de 1932, consta en WESCHLER, Diana, Desde la otra vereda. Momentos en el debate por un arte moderno en la Argentina (18801960), Ediciones Jilguero/Archivos del CAIA 1, Buenos Aires, 1998, p. 153. 
interpretó que el Salón “... aparece como un punto de condensación dentro del proceso desplegado por el movimiento moderno en la Argentina". 47

En agosto Juan Zocchi, una voz consagratoria en el ambiente plástico local, ofreció una conferencia, patrocinada por el Ateneo, en la Biblioteca Argentina donde destacó a Gustavo Cochet y Augusto Schiavoni como los valores artísticos de la ciudad y como pintores fieles al momento. Sobre Cochet sostuvo que trabaja “... dentro de una técnica clásica y nueva a la vez..." y que "... lleva a cabo mucho de lo que quería Cezanne". A Schiavoni lo pensó como "esteta metafísico" que participa "... del clasicismo y primitivismo actual". ${ }^{48}$

En octubre, Cochet reseñó la exposición de su amigo Augusto Schiavoni ${ }^{49}$... para el periódico La Tierra, viendo en Schiavoni al "pintor más dotado" que "haya conocido". Sabemos que la obra del artista resultaba muy distante de las formulas tradicionales, razón por la que el primero trató de crear los parámetros de aproximación que permitieran valorarla e invitó a visitar la muestra para ver “... el verdadero sentido del arte de la pintura”. Advirtió que "... pintores como Schiavoni que son tan profundamente humanos son cada vez más incomprendidos y lo serán cada vez más mientras la sociedad de las gentes no tome otro rumbo" y aconsejaba:

... lo único que puedo es recomendar al que quiera ver la pintura de Schiavoni igual a Goya y al Fray Angélico, que haga abstracción por un momento de la mala pintura que está acostumbrado a ver y contemple con mirada clara y con deseos de comprensión y sólo así verá como la naturaleza muerta № 6 es de una belleza de color incomparable, de un dibujo y composición sin tacha; verá cómo el cuadro de la Sandía №3 de un motivo tan sencillo resulta una joya del arte pictórico. ${ }^{50}$

Aquí aparece nuevamente su idea sobre las cualidades plásticas que debe tener una obra, las que no pasan por el virtuosismo sino por la formulación de "un poema pictórico".

En otro orden, no resulta casual que Cochet haya ponderado las naturalezas muertas de Schiavoni, ya que éste ha sido un género intensamente transitado en el período de entreguerras debido a que resultaba propicio para desplegar "lecciones de pintura". Sobre dicho género Cochet expresó: “... en la naturaleza muerta el pintor en íntimo soliloquio descubre su alma al espectador". ${ }^{51}$ Reconocemos en Cochet una aproximación personal a la noción

47 Ibídem, p. 137.

48 ZOCCHI, Juan, Conferencia del Sr Juan Zocchi sobre 'La vida del arte', Archivo Schiavoni, sin paginar.

49 La exposición de Augusto Schiavoni se realizó en la sede local de la agrupación Signo, en el Salón Bleu de la confitería La Perla. El prólogo del catálogo fue escrito por Emilio Pettoruti.

50 COCHET, Gustavo, “Augusto Schiavoni”, La Tierra, Rosario, 10/10/1932. Archivo Schiavoni, sin paginar.

51 COCHET, Gustavo, Diario ..., Op. Cit., p. 242. 
de "Realismo", en su Diario, el artista apuntaba: "Realismo no quiere decir imitación o copia fría de las cosas de la naturaleza, si es apasionadamente sentida, la "copia' más realísticamente concebida, lleva el poético embeleso y sentimiento que le dé categoría de arte". Para Cochet, "Fidelidad", no significa "servilismo", implica "fe y amor". A lo que agrega “... todo oficio además de manejo de la herramienta comprende la dignidad, el carácter y el acento personal". 52

\section{Toma de posición}

La década del treinta estuvo signada por el recrudecimiento de la lucha ideológica cuyo correlato fue un proceso de politización creciente de la cultura a escala mundial. Artistas, intelectuales y escritores comprometidos con su época conformaron frentes populares para enfrentar al fascismo. En 1934, Cochet, regresó a Barcelona. Ese año se había formado en Rosario la Mutualidad Popular de Estudiantes y Artistas Plásticos, entidad que en 1935 se enrolaría en las filas de la AIAPE (Agrupación de Intelectuales, Artistas, Periodistas y Escritores), nucleamiento fundado en julio de 1935 en Buenos Aires, en el marco de la política de formación de frentes populares ya mencionada. ${ }^{53}$

En su Diario, Cochet, anotó que “... el 19 de junio de 1936 cerré las puertas de mi taller ... ¿en qué podían servirles mis pinturas al pueblo en armas en su magna lucha?". ${ }^{54}$ Luego, en noviembre, organizó dos exhibiciones: una exposición retrospectiva denominada " 25 años de pintura" en la Sala Parés en la que figuraban más de 150 cuadros de diferentes etapas y una muestra de 300 trabajos grabados, litografías, dibujos, acuarelas. Resulta interesante reparar en la reflexión del autor quien señala que “... en ningún momento se me ocurrió cambiar de tendencia o de concepto artístico para estar a tono con la guerra". Cochet se distancia de la idea de un arte para el pueblo o para las masas, ya que, en sus palabras, "... generalmente los artistas que ilustran el mito proletario, son perfectos y acabados burgueses". ${ }^{55}$

Encausó su compromiso con la República integrándose a la Confederación Nacional del Trabajo (CNT), perteneciente a la Federación Anarquista Ibérica (FAI). Fue Secretario de Propaganda y Organización del Casal de la Cultura de Barcelona, desde donde impulsó la propuesta de que "... el obrero llegue a poder conseguir y adquirir obras de arte con que

52 Ibídem, pp. 196-197.

53 Sobre la AIAPE ver, BISSO, Andrés, CELENTANO, Adrián, "La lucha antifascista de la Agrupación de Intelectuales, Artistas, Periodistas y Escritores (AIAPE) (1935-1943)”, en BIAGINI, Hugo, ROIG, Arturo (directores), El pensamiento alternativo en la argentina del siglo XX: obrerismo, vanguardia, justicia social, 1930-1960, T. II, Biblos, Buenos Aires, 2006, p. 242.

54 COCHET, Gustavo, Diario..., Op. Cit., p.173. Las citas que constan a continuación pertenecen a la misma fuente pp. 172-173.

55 Ibídem, p. 201. 
embellecer su hogar" ${ }^{56}$ restituyendo a los artistas su rol de "humildes obreros" e iniciando el "renacimiento del arte popular". ${ }^{57}$ Cochet sostenía que del Casal de la Cultura debían salir "... las obras que decoraran los ateneos, las bibliotecas, los sindicatos, los teatros, las salas de las asambleas ... los artistas del futuro". 58

Realizó ilustraciones y artículos para los periódicos Tiempos Nuevos y Tierra y Libertad, escribió sobre el sentido del arte, el arte y la religión, el rol del arte en los procesos revolucionarios y el arte y sus destinatarios. Participó del salvataje de obras de arte realizado por la FAI con la convicción de que “... las obras salvadas en la revolución que antes adornaban las casas de los banqueros y comerciantes, deberán en el futuro adornar las casas y locales de los sindicatos o los ateneos donde se reúnan los trabajadores" ${ }^{59}$ En su Diario anotó “... puedo adjudicarme sin jactancia alguna, haber contribuido eficazmente a salvar la demolición de la Catedral de Manesa, una de las más puras de arte gótico en Cataluña". ${ }^{60}$

Las obras recuperadas en la campaña de salvataje fueron expuestas en abril de 1937 en el local de la sección de bellas artes de la CNT. Cochet escribió un prefacio para la muestra que luego fue trasladada a París. Ese año publicó la segunda edición de su Diario de un pintor, creó un Salón Permanente, en sustitución del oficial, en el Casal de la Cultura y cinco de sus óleos ${ }^{61}$ fueron expuestos en la inauguración del nuevo edificio del Museo de Bellas Artes de Rosario.

Entre 1936 y 1938 realizó su serie de treinta aguafuertes sobre los horrores de la guerra denominada Caprichos, retomando la tradición inaugurada por Callot y cultivada por Goya. ${ }^{62}$ En 1939, una vez derrotada la República, se trasladó a Francia donde asistió al entierro de Antonio Machado en Collioure y debió emigrar para preservar su vida, al igual que sus compañeros y amigos. ${ }^{63}$

56 COCHET, Gustavo, Manifiesto de la Sección de Pintores del Casal de la Cultura de Barcelona, texto manuscrito, 1936, Archivo Museo Gustavo Cochet.

57 COCHET, Gustavo, Exposición de los artistas de la C.N.T, texto mecanografiado, 1936, Archivo Museo Gustavo Cochet.

58 Ibídem.

59 COCHET, Gustavo, "Prefacio", en catálogo de la Exposición de obras salvadas por la FAI, 10 de abril de 1937.

60 COCHET, Gustavo, Diario ..., Op. Cit., p.171.

61 Retrato de mi padre, Retrato de bailarina, Lectora, Interior de molino y La cocinera.

62 Un análisis en profundidad de este cuerpo de grabados se encuentra en RIPPA, Laura, Gustavo Cochet. Caprichos, pasión y lucha, Trabajo Final de Postítulo, FHyA/UNR, Rosario, 2008.

63 Un análisis inicial del itinerario de Gustavo Cochet consta en el catálogo exposición, los textos de sala y los sueltos de la muestra Cochet utópico, Rosario, Centro Cultural Parque de España, noviembre 2010 a febrero 2011, con la curaduría de María Eugenia Prece y la investigación histórica a mi cargo. 


\section{Una forma general de ver y sentir la vida}

Gracias a poseer pasaporte argentino la familia Cochet, conformada por Gustavo, Francisca y Fernando, se salva de ser trasladada a campos de concentración en Francia y es repatriada a nuestro país. ${ }^{64}$ Con respecto a su nacionalidad el artista señalaba:

En Argentina, provincia de Santa Fe, y a orillas del Paraná nací, hijo de un francés rubicundo y de una criolla santafesina. Entre Cataluña y Francia he pasado la mitad de mi vida; en la primera de éstas conocí el amor, aprendí a trabajar, fui feliz. En Francia despertóse mi herencia espiritual paterna, mi cultura es francesa. De la Argentina llevo en lo más hondo de mi ser, como marca indeleble, la llanura de la pampa que significa en mí: atavismos de horizontes sin límites. ${ }^{65}$

En 1939 publicó en el periódico La Vanguardia un artículo denominado "El caracol”66 donde exaltó la figura del vagabundo como paradigma del "hombre libre", como aquel que logra el desapego respecto de los bienes materiales. En esa dirección, en su Diario apuntó "... siempre me basta lo que tengo, nunca tengo más de lo que necesito". ${ }^{67}$ Ese año figuró entre los expositores de la muestra Panorama del grabado desde Sívori hasta hoy organizada por Luis Falcini en el Mueso Nacional de Bellas Artes; inauguró en octubre una exposición individual en la Galería Müller de Buenos Aires y residió por un tiempo en Luján.

Cochet regresó a la Argentina en un momento de institucionalización del arte moderno. En sintonía con el clima modernizador se extendieron las instituciones de enseñanza artística, se abrieron múltiples galerías de arte, se impulsaron nuevos certámenes artísticos y creció el número de coleccionistas. Entre 1941 y 1946, residió en la ciudad de Santa Fe. Se dedicó con intensidad a la producción, participó de salones municipales, provinciales y nacionales y escribió su libro El grabado, historia y técnica ${ }^{68}$ También dictó clases en la Escuela Pro-

64 Comunicación de Silvia Cochet, abril de 2010

65 COCHET, Gustavo, Diario ..., Op. Cit., p.51.

66 COCHET, Gustavo, "El caracol”, La Vanguardia, 20/08/1939. La nota está acompañada por un grabado del artista que exhibe en primer plano a un vagabundo caminando por un sendero. La valoración positiva de la figura del vagabundo es característica de los simpatizantes de las ideas libertarias. Hemos analizado la aproximación a esta figura en la obra de Cochet y de Ricardo Sívori en FLORIO, Sabina, RODRÍGUEZ, Jimena, "Ricardo Sívori: de las nuevas formas del realismo a la síntesis plástico-realista”, en Revista Historia Regional, Sección Historia, ISP № 3, № 28, 2010, pp. 59-75.

67 COCHET, Gustavo, Diario..., Op. Cit., p.151.

68 Publicado por la editorial Poseidón en 1943. Un análisis sobre el libro de Cochet, su impacto en los grabadores locales y la institucionalización de la disciplina en el ámbito del Museo consta en FLORIO, Sabina y RIPPA, Laura, ponencia "El grabado en la Argentina: un aporte para el "conocimiento" de la historia del arte nacional", Terceras Jornadas sobre Exposiciones de Arte Argentino 
vincial de Artes Plásticas, creada en 1940, dirigida inicialmente por Sergio Sergi y luego por José Planas Casas. Por entonces, en la capital de la provincia confluyeron creadores de distintas procedencias quienes generaron una dinámica enriquecedora en su vida cultural.

En Santa Fe eligió como vivienda una casa a imagen y semejanza de su arte al igual que lo habían hecho Manuel Musto y Augusto Schiavoni en el barrio Saladillo en los años '20 también, Santiago Minturn Zerva cuyo hogar era “... una mezcla de taller y vivienda...”, en la que "... dominaba un olor a naranjo proveniente del patio donde coexistían cientos de macetas" ${ }^{69}$ En su Diario, Cochet, se refirió a "los dos grandes naranjos" del patio de la casa de Santa Fe. ${ }^{70}$

En un escrito sobre Santiago Minturn, Cochet, enumeró un elenco de temas cultivados por el primero: “... los patios humildes, macetas con plantas de malvones y otras flores...", "figuras y objetos sencillos", “... elementos propios del ambiente familiar, común y cotidiano que le era tan querido". Caracterizó éste tipo de elecciones como una “... forma general de ver y sentir la vida". Definió a su amigo como:

... un gran solitario... [que] ... solía tomar su caja de acuarelas e irse a pintar por las cercanías de la ciudad: algunos árboles, alguna casa de chacra solitaria con sus parvas y su molino de viento en el dilatado espacio, los yuyos y gramillas con los alambres que a lo largo de los caminos bordean sus márgenes ... Todos eran elementos suficientes para elegir entre ellos los motivos para sus cuadros. ${ }^{71}$

Preferencias estéticas y motivos que encontramos también en el autor de las líneas y en un conjunto de artistas radicados en Rosario que constituyeron una alternativa estética regional.

En un mismo sentido, Cochet escribió “... todavía encuentro la emoción poética en el viejo tapial de mi patio, con sus descascarados muros" ${ }^{72}$ Manuel Musto también entendía que "un objeto pictórico" debía serlo "... por la emoción pictórica que da". ${ }^{73}$ Siguiendo a Cochet "... el pintor debe salir a la luz, ir hacia la naturaleza, hacia el encuentro de la vida en un sentido universal hondamente sentido y hallará sus motivos a cada instante". ${ }^{74}$

y Latinoamericano "El rol de los museos y los espacios culturales en la interpretación y la difusión del arte", Grupo de Estudios sobre Exposiciones de Arte Argentino y Centro Cultural Parque España / AECID, Rosario, 15, 16 y 17 de junio de 2011.

69 La caracterización de la casa-taller corresponde al sobrino nieto del artista, Arnoldo Gualino, y consta en el libro Santiago Minturn Zerva. Obra xilográfica, Rosario, EBA/UNR/Editorial Municipal de Rosario, 1996, p. 13.

70 COCHET, Gustavo, Diario..., Op. Cit., p. 229.

71 COCHET, Gustavo, La Capital, Rosario, 09/09/1976. (Archivo Cochet, sin paginar)

72 COCHET, Gustavo, Diario ..., Op. Cit., p. 229.

73 MUSTO, Manuel, Cuaderno..., Op. Cit., p.71.

74 COCHET, Gustavo, Diario ..., Op. Cit., p. 233. 
También reflexionó en torno al vínculo con las tradiciones: “... echando una mirada hacia atrás, nos encontramos con Courbet, Delacroix, Chardin, Corot, Fantin Latour, retomaremos entonces de nuevo el hilo de la verdadera tradición, adaptándonos desde luego a las conquistas del arte moderno que culminó con los impresionistas sobre todo Cézanne, Renoir y Manet”. Así, concluye: “... yo, estoy con los que siguen este camino e intuyo que por esta razón estoy... entre los precursores del arte del mañana". ${ }^{75}$

Las miradas a la "verdadera tradición" cruzadas con "... las conquistas del arte moderno..." se tornan explícitas, al menos, en dos obras que funcionan como cuadros-manifiesto. Al respecto percibimos en Cochet, un rasgo que detectamos también en Augusto Schiavoni, nos referimos a que hay determinadas obras-clave, donde los artistas muestran lo que miran y lo enlazan con un conjunto de tradiciones propias del género cultivado para su plasmación. ${ }^{76}$ La primera obra aludida es Desnudo dormida donde Cochet retomando la tradición de las "Venus sorprendidas", yuxtapone a la figura recostada de su esposa Francisca una publicación donde consta el nombre: Renoir. La segunda, es una naturaleza muerta denominada Homenaje a Chardin donde, en un bodegón de cocina sólidamente construido, aparece suspendido sobre la mesa, ubicada en un primer plano, un papel que tiene escrito el nombre: Chardin.

En septiembre 1943, para celebrar sus "bodas de plata como pintor" realizó una importante y consagratoria exposición en el Museo Provincial de Bellas Artes "Rosa Galisteo de Rodríguez". Un extenso catálogo, que ostenta en su tapa un hermoso retrato de Francisca, acompañaba la muestra. El prólogo, a cargo de Horacio Caillet-Bois por entonces Director del Museo, afirmaba que "... hay un encanto tan jocundo de vida sana y de sabrosa vitalidad en los cuadros de Cochet, que frente a ellos experimentamos un goce físico y espiritual a la vez". ${ }^{77} \mathrm{El}$ autor sostiene que "... lo mismo que los viejos maestros del Setecientos, enamorados de la vida rabelesiana las obras de este pintor comunican a quien las contempla un bienestar de los sentidos...", así sus paisajes y naturalezas muertas “... tienen como los de Chardin ... el sabor de los manjares exquisitos, que son los ganados con el sudor de la frente".

Caillet-Bois define al rosarino como un "... hombre bueno y buen pintor..." y aclara que el artista eligió acompañar su presentación con la palabra de sus amigos en lugar del juicio de la crítica, manteniendo así nuevamente su firme postura libertaria. En el "Colofón” del

75 Ibídem, p. 238.

76 En nuestra ponencia "Entre la vanguardia y la tradición. Augusto Schiavoni y Gustavo Cochet", desarrollamos la implementación de miradas activas a la tradición desplegadas por por ambos artistas rosarinos. En las IX Jornadas de Arte e Investigación "El arte de dos siglos: balance y futuros desafíos", Instituto de Teoría e Historia del Arte "Julio E. Payró", Buenos Aires, 24, 25 y 26 de noviembre de 2010.

77 CAILLET-BOIS, Horacio, “Umbral”, en Catálogo Exposición de Gustavo Cochet en sus bodas de Plata, MPBARGR, Santa Fe, septiembre, 1943, pp. 3-4. Las frases citadas a continuación corresponden al mismo texto. 
catálogo se deja constancia de que los artistas, poetas y escritores que figuran en el mismo “... han querido testimoniar al expositor su simpatía y cordial adhesión en oportunidad tan significativa para él". Así, José Pedroni le dedica un poema que celebra su vida y su obra; ${ }^{78}$ Minturn Zerva, Pere Daura, Carlos Giambiagi, Sergio Sergi, César López Claro, Ricardo Suspiciche, y José Planas Casas aportaron sus grabados. Alfredo Guido, Miro Bardonek, Eugenio Fornells, Lino E. Spilimbergo, César Fernández Navarro, George Deniker y Enrique Cenac enviaron dibujos; Luis Falcini un bajorrelieve y Antonio Sibellino un "estudio para un relieve". Enrique Estrada Bello dibujó a Cochet en su taller, de espaldas frente a su caballete, realizando un autorretrato y rodeado por una pintura de gran formato de Francisca y Fernando, unos cuadros de mujeres desnudas y una valija con carteles que indican España, París, Buenos Aires, Santa Fe y Rosario.

Agustín Zapata Gollán escribió un texto que compone el semblante de Cochet con su “... barba florida, su pipa abatida entre sus labios, sus sandalias ascéticas, su recio cinto de cuero..." y su bondad que surge de "... su radiante corazón de niño" ${ }^{79}$ Con respecto a su obra, propone pensarla como “... las páginas de una autobiografía..." y al artista como alguien que "... siente una verdadera pasión por su oficio...", que encuentra sus motivos “... en las callejas de París con sus empinadas techumbres de pizarra, o en los barrios de Barcelona con sus humeantes chimeneas, o en los policromos caseríos de Cataluña, o en los pequeños pueblos de pescadores de Francia, como en el campo de su patria". También destaca otra arista en sus proposiciones plásticas, la de los interiores, ya que "... como un viejo holandés, planta su caballete en su aposento y amorosamente, va reflejando en sus telas, la vida hogareña". En sus cuadros residen “... las compras del mercado, la mesa tendida, el pan dorado y fresco, la albura de los manteles, el botellón de agua pura, el pequeño aparador de vajilla modesta y pulcra, la botella de vino generoso, el vaso de cristal donde amustian unas flores junto al reloj". Finalmente, percibe en sus interiores "... un contenido dolor, quizás ese contenido dolor que, después de las sombrías jornadas de desolación y de muerte que vieron en Europa sus ojos de hombre bueno, le llevó a encerrar su vida en el refugio del hogar". ${ }^{80}$

Leonidas Barletta habla de su "... raza de campesino y artesano ... con la pipa en la boca y el buril en la mano..." y “... sus diez dedos como diez pinceles..." ${ }^{81}$ Juan Zocchi lo define como un caso de “... comprobada identificación del hombre con el artista...", sostiene que

78 En su Diario..., Cochet declara su “... admiración por nuestros máximos poetas, mis paisanos del litoral José Pedroni y Carlos Carlino”. Cochet, Gustavo, Diario..., Op. Cit., p. 209.

79 ZAPATA GOLLÁN, Agustín, "Loor de Gustavo Cochet”, en Catálogo Exposición ..., Op. Cit., pp. $8-10$.

80 Silvia Cochet nos ha señalado en reiteradas oportunidades el dolor por la derrota de la República que marcó a su abuelo para toda su vida.

81 BARLETTA, Leonidas, “Gustavo Cochet”, en Catálogo Exposición ..., Op. Cit., p. 11-12. 
“... Cochet tiene una experiencia y una maestría que, reunidas con su visión del mundo, su carácter personal y su sentimiento artístico hacen un modo, un estilo particular..." y afirma que sus obras “... son una nota que ningún otro artista ha dado y que completará la pintura argentina, ampliando su horizonte y definiéndola mejor". 82

Carlos Carlino le dedica un poema de bienvenida, George Deniker le envía una afectiva carta en francés, Armando Molina afirma que "... nada se parece tanto a Cochet como su propia obra pictórica...”, que en sus producciones “... vibran al unísono la verdad y la poesía, una poesía a lo Whitman". ${ }^{83}$ Enrique Cenac rememora la confluencia de ambos en la Galería Dalmau y destaca la coherencia del artista quien se erige en un ejemplo. Finalmente, Luis Lauzet lo define como aquel que nunca se apartó "... del digno oficio de crear belleza" ${ }^{84} \mathrm{Con}$ respecto al conflictivo tema de las vinculaciones del arte con la sociedad, el autor sostiene un concepto similar al que Cochet expresara en su Diario de un pintor, así "... el alud de horrores que invadió gran parte del mundo...", no es materia para "expresiones auténticas de arte". "Esos acontecimientos piden manifestaciones de otro orden. Por eso Cochet graba y pinta bien, con sabia ternura, paisajes, figuras, marinas, escenas de trabajo."

Otra muestra consagratoria para el artista fue la realizada al año siguiente en la Galería Müller de Buenos Aires. El catálogo que acompañó la exhibición operó como una actualización de su Diario de un pintor cuya primera edición data de 1932. En el prólogo aclara que retoma la narración después de la reedición de su libro lanzada por la Editorial Conducta del Teatro del Pueblo en 1942. Sus primeras reflexiones exaltan el oficio y expresan su desconfianza sobre los tratados de pintura a los que declara temer "... como a las peores compañías..." ${ }^{85}$ Llama a "... volver a la naturaleza, a la tierra...", reivindica la amistad como energía, como "reconfortamiento espiritual" con las que "... el artista puede realizar su obra". Recomienda estudiar en un taller más que en una escuela, puesto que el que se forma en un taller "sabe para qué aprende", en tanto que, según el autor, quien asiste a la escuela "... lo hace para conseguirse un título".

También, reflexiona sobre las causas que llevaron al mundo a la guerra, siendo éstas el "materialismo y el realismo científico" y finaliza la publicación con un cuerpo de ideas bajo el título "Mi credo" donde declara ser "un libre pensador", amar el buen vino y la naturaleza y anhelar "... la libertad para el mundo entero".

Asimismo, un reconocimiento importante para el artista, fue la inclusión en el libro Veintidós pintores argentinos del prestigioso crítico y difusor de los principios del arte

82 ZOCCHI, Juan, "Retrato de Gustavo Cochet y su pintura", en Ibídem, p. 17-18.

83 MOLINA, Armando E., "Gustavo Cochet, Hombre fiel a su destino”, en Ibídem, p. 22-23.

84 LAUZET, Luis, "Gustavo Cochet. Pintor y grabador", en Ibídem, p. 25-26.

85 Catálogo Exposición de pinturas de Gustavo Cochet, Galería Müller, Buenos Aires, octubre 1944, p. 7. La publicación posee 56 páginas. Las frases citadas a continuación corresponden al mismo texto. 
moderno, Julio Payró. En abril de 1945 expuso en la Galería Witcomb de Rosario, obtuvo el Primer Premio Adquisición en el Salón de Santa Fe y publicó Honoré Daumier. ${ }^{86}$

Otra de las características marcadas del período fue la consolidación de diversas agrupaciones de carácter gremial que buscaban operar como elemento de presión ante las instituciones artísticas y las políticas culturales oficiales. Con respecto a las prácticas impulsadas por las agremiaciones locales Cochet sostuvo una posición crítica haciendo pública su renuncia a la filial santafesina de la Sociedad de Artistas Plásticos en julio de $1945 .{ }^{87}$ Pensamos que Cochet percibía que la problemática real pasaba por lograr que el pintor pueda vivir de su trabajo, que sea "su oficio" el que le dé "el pan”. Así, “... toda lucha y competición entre artistas debiera realizarse en lindes donde lo que se ponga en juego, no sean cátedras, premios u otras prebendas burocráticas, sino el sagrado ideal del arte" ${ }^{88}$ Cochet pugnaba por que los artistas trabajaran activamente en la ampliación de las audiencias y de los consumidores de bienes simbólicos, en lugar de insistir en las instancias de certámenes y premios como eje central de sus discursos y proclamas. ${ }^{89}$

\section{Miradas activas hacia Cochet}

Cochet regresó a Rosario en 1947 y publicó Entre el llano y la sierra.$^{90}$ En 1948 lanzó la cuarta edición de Diario de un pintor ${ }^{91}$ y fue nombrado Profesor Adjunto de la asignatura "Figura y Ornato" en la Escuela de Arquitectura de la Universidad Nacional del Litoral. En 1956 fue dejado cesante en su cargo por decisión de la dictadura militar autodenominada como "Revolución Libertadora". El artista vivió su destitución como una brutal injusticia y manifestó por escrito la arbitrariedad de la que fue objeto, dejando constancia de que su acceso a la cátedra fue “... ganado por concurso sin mediar ningún servil sometimiento y sin

86 Editado por la editorial Poseidón.

87 Carta de Gustavo Cochet dirigida al Señor Francisco Puccinelli Presidente de la Sociedad de Artistas Plásticos de Santa Fe, fechada el 12 de julio de 1945, Archivo Museo Gustavo Cochet.

88 COCHET, Gustavo, Diario ..., Op. Cit., p. 234.

89 Por entonces se las filiales santafesina y rosarina de la Sociedad Argentina de Artistas Plásticos sostenían políticas de enfrentamiento con los criterios de conformación de los jurados de selección y premios del Salón de Otoño, en el marco de la gestión de Hilarión Hernández Larguía como Director del Museo Municipal de Bellas Artes "Juan B. Castagnino". Una zona de los acalorados debates, la hemos abordado en nuestro trabajo "Manuel Ferrer Dodero, intérprete de su entorno", en catálogo exposición Un arte serero y perdurable. Manuel Ferrer Dodero, Funes, Museo Gustavo Cochet, setiembre 2010, con la curaduría a mi cargo.

90 Publicado por la editorial Castellvi de Santa Fe.

91 También publicado por la editorial Castellvi. 
ocupar el lugar de nadie por ser cargos nuevos". ${ }^{92}$ Asimismo consignó que " ... resulta incomprensible el porque de tan exclusivo y encarnado rigor contra los profesores universitarios". ${ }^{93}$

Luego, fijó su residencia en Funes y entre 1955 y 1963 dictó clases en la Escuela de Bellas Artes de Pergamino donde tuvo entre sus jóvenes alumnos a Juan Pablo Renzi. En el marco del rastreo de prácticas soslayadas, en 1958, Emilio Ellena lanzó una colección de carpetas de estampas “... marcando un primer ciclo en la revisión y rescate de la gráfica argentina" ${ }^{94}$ La primera carpeta - de un conjunto de cincuenta en total- estuvo dedicada a Gustavo Cochet. En un mismo sentido, Cochet, figuró entre los expositores de la muestra Veinticinco años de pintura Rosarina -realizada en agosto de 1964 en la Galería Carrillo-y de la Exposición de pintura Rosarina. Colección Isidoro Slullitel -presentada en el Museo Municipal de Bellas Artes "Juan B. Castagnino" en 1965-. Ambas muestras intentaban recuperar la actuación de los artistas modernos iniciales, invisibilizados por el prestigio ostentado por el Grupo Litoral. En palabras de Juan Grela intentaban reunir “... los eslabones dispersos de nuestra vida artística con un sentido de totalidad destinado a mostrar el panorama completo de nuestra idiosincrasia plástica". ${ }^{95}$

En 1967 se realizó la exposición de la colección de Slullitel denominada Pintura actual de Rosario en el Museo Municipal de Bellas Artes "Juan B. Castagnino". Según Rubén Naranjo - miembro del grupo de vanguardia- “... los vanguardistas autores de algunas de las obras, impusieron el nombre de Cochet para la presentación inaugural". ${ }^{96}$ La razón de su convocatoria se debía, como ha mencionado Juan Pablo Renzi, a que "... la gente se había acercado mucho" a él. ${ }^{97}$ Naranjo aprovechó la coyuntura para retomar la polémica mantenida con el Grupo Litoral, cuyo momento álgido había sido el lanzamiento del suelto "A propósito de la cultura mermelada" el año anterior. Así, siguiendo a Naranjo “... a los 74 años, Gustavo Cochet, ve con más claridad que los anquilosados pintores modernos,

92 Carta de Gustavo Cochet dirigida al Doctor José María Fernández Interventor de la Universidad del Litoral, fechada en febrero de 1956, Archivo Museo Gustavo Cochet.

93 Ibídem.

94 DOLINKO, Silvia, Arte para todos. La difusión del grabado como estrategia para la popularización del arte, Fundación Espigas, Buenos Aires, 2003, p. 42.

95 GRELA, Juan, catálogo Exposición de pintura Rosarina. Colección Isidoro Slullitel, Museo Municipal de Bellas Artes "Juan B. Castagnino", Rosario, 10 al 31 de oct, 1965. Cabe agregar que Grela fue -junto a Ellena, Sllulitel, Carrillo y Gambartes- uno de los principales impulsores de estas recuperaciones. Además Grela fue asesor de Slullitel en la conformación de su colección de arte local.

96 NARANJO, Rubén, “El revés de la trama”, Boom, Rosario, set. 1968.

97 FANTONI, Guillermo A., Arte, Vanguardia y politica en los años '60. Conversaciones con Juan Pablo Renzi, El Cielo por Asalto, Buenos Aires, 1998, p. 45. Renzi reconocía en Cochet al artista que lo había puesto “... en contacto con la verdadera pintura”, cuando tenía 15 años. Fue Cochet quien lo puso en contacto con Grela y Gambartes cuando se radicó en Rosario. 
institucionalizados como máximos exponentes del arte del litoral..." y sus palabras “... superan la estática mediocridad del Museo Municipal”. Naranjo, en el artículo ya citado, implementó una lectura política de la figura de Cochet. ${ }^{98}$

Al modo vanguardista Naranjo apeló al montaje de imágenes contrapuestas y dispuso una fotografía de la fachada del Museo Municipal de Bellas Artes "Juan B. Castagnino", con el subtítulo "la cara de la mentira" junto a una fotografía de Gustavo Cochet, con el subtítulo "la cara de la verdad". ${ }^{99}$ Esta yuxtaposición inquietante proponía desmontar la lectura de la confrontación entre la vanguardia y el arte oficial por la vía de la rebelión generacional, así Naranjo escribía “... los jóvenes plásticos integrantes de la vanguardia rosarina, rodearon al viejo maestro, quizás porque saben que Cochet es una verdad". 100

En 1967, Cochet regresó a Europa después de haber sido deportado en el `39, allí pudo recuperar las obras que había tenido que dejar escondidas debido a las complejas circunstancias que lo aquejaban por entonces. Con el material recuperado, "el infatigable Emilio Ellena," 101 en 1968, organizó la muestra Gustavo Cochet. Exposición Retrospectiva, en el Museo Municipal de Bellas Artes "Juan B. Castagnino". A la par de la exposición se lanzó la publicación denominada Gustavo Cochet, con textos de Mele Bruñard y Eduardo Serón y una selección de pensamientos de Cochet a cargo de Emilio Ellena.

Emilio Ellena acude a Historia de mi vida de Joaquín Torres García y al Diario de un pintor de Cochet para construir su relato. Recrea sus viajes y desplazamientos entre Barcelona, París y Rosario. Habla de la amistad que hermanó al rosarino y el uruguayo, las discusiones que mantuvieron y los hermosos retratos de las hijas de Torres, Ifigenia y Olimpia, pintados por Cochet. Refiere a su participación en la España Republicana, la militancia en la FAI, la realización de los Caprichos puesto que el autor “... rara vez pinta 'temas políticos', eso lo deja para los grabados".

Mele Bruñard reseña sus grabados donde estampa “... con veracidad su mundo de todos los días: su hijo dormido, su mujer cosiendo, su calle desierta, la ciudad silenciosa o envuelta en el bullicio de una feria, los campos de sus paseos, las gentes humildes que fueron sus mejores amigos". Eduardo Serón analiza su pintura y percibe que en sus cuadros están

98 Un análisis de estas posiciones consta en RODRÍGUEZ, Jimena, "Anselmo Piccoli frente al accionar del Grupo Rosario: diferencias y complicidades", Documento de Trabajo, 2010. (mimeo). Emilio Ghilioni -miembro del Grupo Rosario- me ha confirmado la aseveración de Renzi.

99 NARANJO, Rubén, “El revés ...”, Op. Cit.

100 En su Diario... Cochet declaba poner toda su esperanza "en la juventud". COCHET, Gustavo, Diario ..., Op. Cit., p. 151.

101 En la nota ya mencionada Naranjo narra el itinerario europeo de Cochet, su regreso a Europa en el '67, la recuperación de sus obras en "... el granero de una vetusta casa de Collioures". También, destaca la "infatigable" labor de Emilio Ellena. 
presentes “... las postulaciones cezanneanas sobre la estructuración de la forma". Afirma que los géneros tradicionales posibilitaron a Cochet "... su sentido de la vida".

En 1973, Rafael Squirru prologó el catálogo de la exposición Gustavo Cochet. Obras realizadas en España, Francia y Argentina entre 1924 y 1973, exhibida en la Galería Rubbers de Buenos Aires, siendo esta instancia una oportunidad de intensa visibilidad a nivel nacional para el artista. Asimismo, en el año 2002, su nieta, Silvia Cochet, junto a un grupo de vecinos residentes en Funes, creó el Museo Gustavo Cochet en la que fuera su casa-taller, generando una experiencia de autogestión acorde con los principios éticos sustentados por el pintor. Desde entonces, las obras, las ideas estéticas y las opciones libertarias del creador iluminan nuestro presente.

Recibido: 05/07/2011

Aceptado: 04/10/2011 